\title{
Salcaprozate Sodium
}

National Cancer Institute

\section{Source}

National Cancer Institute. Salcaprozate Sodium. NCI Thesaurus. Code C75026.

The sodium salt form of salcaprozate, an oral absorption promoter. Salcaprozate sodium may be used as a delivery agent to promote the oral absorption of certain macromolecules with poor bioavailability such as insulin and heparin. 